\title{
PERUBAHAN SIFAT FISIS PELET TANDAN KOSONG KELAPA SAWIT HASIL TOREFAKSI
}

\section{CHANGES IN PHYSICAL PROPERTIES OF OIL PALM EMPTY FRUIT BUNCH PELLETS CAUSED BY TORREFACTION}

\author{
Tri Yulianto ${ }^{1}$, Indra Gumay Febryano ${ }^{1}$, Dewi Agustina Iryani ${ }^{2}$, Agus Haryanto ${ }^{1}$, Udin \\ Hasanudin ${ }^{1}$, Wahyu Hidayat ${ }^{1 凶}$ \\ ${ }^{1}$ Fakultas Pertanian, Universitas Lampung \\ ${ }^{2}$ Fakultas Teknik, Universitas Lampung

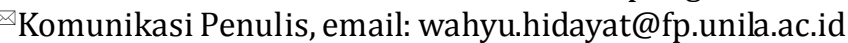 \\ DOI:http://dx.doi.org/10.23960/jtep-lv9i2.104-111
}

Naskah ini diterima pada 29 Maret 2020; revisi pada 29 Mei 2020; disetujui untuk dipublikasikan pada 8 Juni 2020

\begin{abstract}
Oil palm (Elaeis guineensis) empty fruit bunch (EFB) is solid waste derived from palm oil industry and it is promising to be used as source of renewable energy due to its abundance and relatively low price of raw materials. The properties of oil palm EFB can be enhanced for bioenergy application through torrefaction process. Torrefaction is a thermochemical treatment of biomass at temperatures ranging between 200 and $300^{\circ} \mathrm{C}$ and it is generally performed under inert atmosphere. This study aimed to determine the changes in physical properties of oil palm EFB pellets via torrefaction using electric furnace (EF). Torrefaction was conducted at a temperature of $280^{\circ} \mathrm{C}$ with a duration of 20 minutes. The changes in color, density, equilibrium moisture content (EMC), and hygroscopic property of EFB pellets after torrefaction were evaluated. The results showed that the color of oil palm empty fruit bunch pellets totally changed after torrefaction with EF produced the highest $E^{*}$ value of 14.97. Pellet density was $0.58 \% \mathrm{~g} / \mathrm{cm}^{3}$ and after torrefaction with EF it became $0.48 \mathrm{~g} / \mathrm{cm}^{3}$. Moisture content of oil palm empty fruit bunches pellets was $11.54 \%$, and after torrefaction with EF decreased to 6.66\%. Water resistance test shows that the torefaction pellet is more resistant to water than the non-torefaced pellet, so it will be very beneficial when the pellet is use for a long time and in humid conditions.
\end{abstract}

Keywords: color, oil palm empty fruit bunch, pellet, physical properties, torrefaction

\begin{abstract}
ABSTRAK
Tandan kosong kelapa sawit (TKKS) merupakan salah satu limbah padat dari industri minyak sawit yang potensial untuk digunakan sebagai energi terbarukan karena ketersediaannya yang melimpah dan harga bahan baku yang relatif murah. Sifat-sifat TKKS dapat ditingkatkan menggunakan metode torefaksi. Torefaksi adalah perlakuan termokimia pada kisaran suhu $200-300^{\circ} \mathrm{C}$ dengan kondisi inert (oksigen terbatas). Penelitian ini bertujuan untuk mengetahui perubahan sifat fisis pelet TKKS melalui torefaksi dengan menggunakan electric furnace (EF). Torefaksi pelet TKKS pada penelitian ini menggunakan suhu $280^{\circ} \mathrm{C}$ dengan durasi 20 menit. Pengujian pelet TKKS meliputi perubahan warna, kerapatan, kadar air, dan ketahanan terhadap perendaman air. Hasil penelitian menunjukkan bahwa warna pelet tandan kosong kelapa sawit berubah total setelah torefaksi dengan nilai perubahan warna $\left(E^{\star}\right)$ sebesar 14,97. Kerapatan awal pelet sebesar $0,58 \% \mathrm{~g} / \mathrm{cm}^{3}$ menurun dan setelah torefaksi menjadi $0,48 \mathrm{~g} / \mathrm{cm}^{3}$. Kadar air awal pelet tandan kosong kelapa sawit sebesar $11,54 \%$ menurun setelah torefaksi menjadi 6,66\%. Uji ketahanan terhadap air menunjukkan bahwa pelet yang ditorefaksi lebih tahan terhadap air dibandingkan pelet yang belum ditorefaksi, sehingga sangat menguntungkan ketika pelet disimpan dalam waktu yang lama dan pada kondisi lembab.
\end{abstract}

Kata kunci: sifat fisis, tandan kosong kelapa sawit, torefaksi, warna 


\section{PENDAHULUAN}

Biomassa didefinisikan sebagai produk organik dari pertanian, perkebunan dan kehutanan yang dikembangkan untuk bahan bakar, dari limbah dan fasilitas pengolahan limbah. Biomassa dapat dihasilkan secara langsung sebagai produk atau limbah dari pengolahan hasil perkebunan atau kehutanan (Panwar et al., 2011). Salah satu biomassa yang melimpah dari limbah perkebunan adalah tandan kosong kelapa sawit (TKKS). Pada tahun 2015 luas lahan perkebunan kelapa sawit di Indonesia sekitar 10 juta ha, dengan rincian perkebunan kelapa sawit rakyat sekitar 4 juta ha, perkebunan kelapa sawit milik Badan Usaha Milik Negara (BUMN) 0,7 ribu ha dan perkebunan kelapa sawit swasta sekitar 5 juta ha (Direktorat Jenderal Perkebunan, 2014).

Salah satu potensi pemanfaatan limbah TKKS yaitu sebagai sumber bioeneregi. Pemanfaatan TKKS sebagai bioenergi dapat dilakukan dengan proses densifikasi, yaitu pemadatan biomassa dengan cara pengempaan/penekanan sehingga rapat massa dan kerapatan potensi energinya meningkat (Syamsiro, 2016). Produk yang dihasilkan dari proses densifikasi salah satunya ialah pelet biomassa. Namun, pelet biomassa memiliki kekurangan diantaranya tidak dapat disimpan lama dan memiliki daya serap air yang tinggi serta nilai kalor yang relatif rendah (Rani et al., 2020; Rubiyanti et al., 2019). Teknologi torefaksi dapat digunakan untuk pengolahan pelet biomassa agar kualitas meningkat dan biomassa dapat dipergunakan dalam rentang waktu lama (Basu, 2013).

Torefaksi merupakan proses pemanasan bahan baku biomassa dengan suhu yang terkendali antara $200{ }^{\circ} \mathrm{C}-300^{\circ} \mathrm{C}$. Proses torefaksi ini membawa perubahan karakteristik struktur biomassa tersebut menjadi arang yang keras dan ulet (Nur, 2014). Torefaksi dilakukan untuk mengetahui perubahan visual warna pada pelet TKKS dan pengaruh suhu torefaksi terhadap sifat fisis pelet TKKS. Pada penelitian ini, pengolahan pelet TKKS menjadi sumber energi biomassa dilakukan dengan menggunakan electric furnace (EF). Penelitian ini bertujuan untuk mengetahui pengaruh torefaksi dengan EF terhadap perubahan sifat fisis pelet tandan kosong kelapa sawit meliputi perubahan warna kadar air, nilai kerapatan, dan ketahanan terhadap air.

\section{BAHAN DAN METODA}

Penelitian ini dilakukan pada bulan JuliDesember 2019 di Workshop Laboratorium Teknologi Hasil Hutan Laboratorium Lapang Terpadu, Laboratorium Teknologi Hasil Hutan, dan Laboratorium Daya dan Mesin Pertanian, Fakultas Pertanian, Universitas Lampung. Bahan utama yang digunakan berupa pelet tandan kosong kelapa sawit (TKKS) yang telah disiapkan lalu dilakukan penyaringan menggunakan saringan (strainer) dengan tujuan memisahkan pelet TKKS dengan debu dan serbuk sisa pelet.

Pelet TKKS yang digunakan memiliki ukuran panjang 1-2 cm dengan diameter 0,85-0,88 cm. Sampel pelet TKKS kemudian disimpan dengan menggunakan kontainer plastik untuk menjaga pelet dari kelembaban udara. Pelet TKKS dibungkus dengan aluminium foil yang dilubangi pada setiap sisinya untuk mencegah pembakaran selama proses torefaksi (Gambar 1). Torefaksi dengan electric furnace (EF) dilakukan pada suhu $280^{\circ} \mathrm{C}$ dengan durasi 20 menit.

Pengujian warna dan sifat fisis dilakukan terhadap pelet TKKS sebelum dan setelah ditorefaksi. Pengujian perubahan warna dilakukan dengan menggunakan sistem CIE- $L a b$ dengan mengukur parameter warna kecerahan $\left(L^{*}\right)$, kromatisasi merah/hijau $\left(a^{*}\right)$, dan kromatisasi kuning/biru $\left(b^{*}\right)$. Perubahan warna secara keseluruhan $\left(E^{*}\right)$ dapat dihitung menggunakan Persamaan 1 (Esteves dan Pereira, 2009):

$$
\Delta E^{*}=\left(\Delta *^{2}+\Delta a^{2}+\Delta b^{2}\right)^{1 / 2}
$$

Dimana, $\mathrm{L}^{*}, \mathrm{a}^{*}$, dan $\mathrm{b}^{*}$, secara berurutan adalah perubahan kecerahan, perubahan kromatisasi merah/hijau, dan perubahan kromatisasi kuning/biru setelah torefaksi.

Derajat perubahan warna ditentukan berdasarkan klasifikasi (Valverde dan Moya (, 2014): 


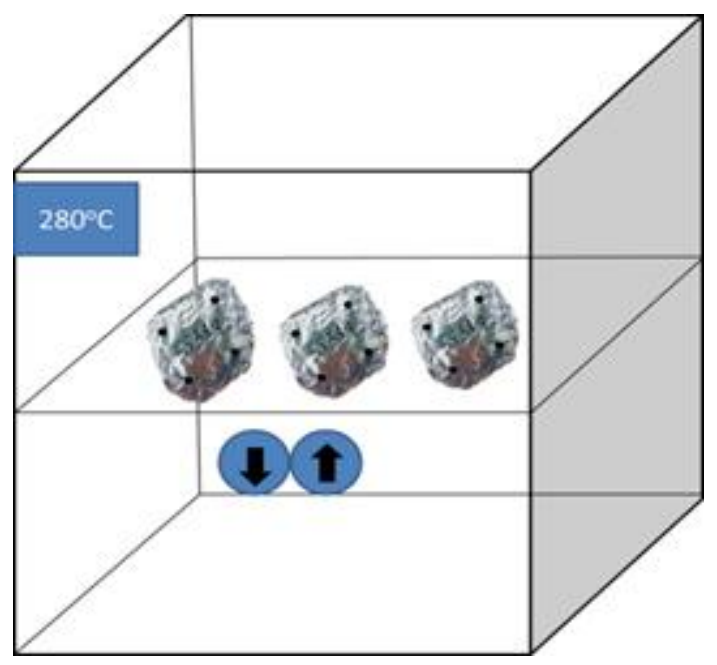

Gambar 1. Skema Torefaksi Menggunakan Electric Furnace

$0,0<\mathrm{E}^{*}=0,5=$ perubahan dapat dihiraukan

$0,5<E^{*}=1,5=$ perubahan warna sedikit

$1,5<E^{*}=3=$ perubahan warna nyata

$3<\mathrm{E}^{*}=6=$ perubahan warna besar

$6<\mathrm{E}^{*}=12=$ perubahan warna sangat besar

$\mathrm{E}^{*}>12=$ warna berubah total.

Sifat fisis yang diamati meliputi kerapatan, kadar air, dan ketahanan terhadap perendaman air. Pengujian kerapatan dilakukan pada kondisi kering tanur berdasarkan standar SNI 01-62352000 (Badan Standardisasi Nasional 2000) dengan mengukur berat dan volume sampel dan dihitung dengan Persamaan 2.

$$
K R=\frac{m}{v}
$$

Dimana, $K R$ adalah kerapatan $\left(\mathrm{g} / \mathrm{cm}^{3}\right), m$ adalah massa pelet (gram), dan $v$ adalah volume pelet $\left(\mathrm{cm}^{3}\right)$.

Pengujian kadar air dilakukan berdasarkan standar SNI 8021.2014. Berat kering udara dan berat kering tanur diukur untuk menentukan kadar air sampel sebelum dan setelah torefaksi. Kadar air (KA) dihitung dengan Persamaan 3.

$$
K A=\frac{(B A-B K T)}{B A} * 100 \%
$$

Dimana, $K A$ adalah kadar air (\%), $B A$ adalah berat awal (g), dan $B K T$ adalah berat kering tanur (g).

Uji ketahanan terhadap air dilakukan dengan merendam pelet kayu jabon ke dalam air dan dilihat perubahan visual yang terjadi pada pelet kayu jabon setelah perendaman selama 5 , dan 30 menit, serta 1,6 , dan 12 jam.

\section{HASIL DAN PEMBAHASAN}

\subsection{Perubahan Warna}

Perubahan nilai parameter warna pelet TKKS dapat dilihat pada Tabel 1. Hasil penelitian menunjukkan bahwa pada sampel sebelum torefaksi (kontrol) pelet TKKS memiliki kecerahan $\left(L^{*}\right)$ tertinggi, dan nilai $L^{*}$ menurun setelah torefaksi. Kromatisasi merah/hijau $\left(a^{*}\right)$ pelet TKKS mengalami penurunan setelah torefaksi. Kromatisasi kuning/biru $\left(b^{*}\right)$ menunjukkan tren yang sama dengan nilai $L^{*}$ dan $\mathrm{a}^{*}$, dimana nilai $b^{*}$ semakin menurun setelah torefaksi.

Perubahan warna keseluruhan $\left(E^{\star}\right)$ pada gambar 3 pelet TKKS mengalami peningkatan setelah torefaksi. Tabel 1 menunjukkan bahwa $E^{*}$ setelah torefaksi pada suhu $280^{\circ} \mathrm{C}$ memiliki nilai $>12$, dengan kata lain warna pelet yang ditorefaksi berubah total. Perlakuan panas terhadap kayu dapat menyebabkan perubahan warna karena terjadi degradasi hemiselulosa (Hidayat et al., 2017; Hidayat et al., 2018). Sampel kontrol memiliki warna yang lebih terang, namun saat suhu pemanasan mencapai $220^{\circ} \mathrm{C}$ warna sampel menjadi lebih gelap. Menurut Karlinasari et al. (2018) perlakuan pemanasan terhadap kayu memberikan pengaruh bahwa hingga suhu $180^{\circ} \mathrm{C}$ terjadi perubahan warna secara visual menjadi lebih 
Tabel 1. Perubahan Parameter Warna Pelet Tandan Kosong Kelapa Sawit (TKKS)

\begin{tabular}{|c|c|c|c|c|c|c|c|}
\hline No & Perlakuan & $\begin{array}{c}\text { Suhu } \\
\left({ }^{\circ} \mathrm{C}\right)\end{array}$ & $\begin{array}{c}\text { Durasi } \\
\text { (menit) }\end{array}$ & $\mathbf{L}$ & $\mathbf{A}$ & b & $\Delta \mathbf{E}$ \\
\hline 1 & Kontrol & & & $\begin{array}{l}33,63 \\
(2,10)\end{array}$ & $\begin{array}{c}3,97 \\
(0,67)\end{array}$ & $\begin{array}{c}6,73 \\
(4,08)\end{array}$ & - \\
\hline 2 & $\begin{array}{l}\text { Electric } \\
\text { Furnace }\end{array}$ & 280 & 20 & $\begin{array}{l}20,10 \\
(2,04)\end{array}$ & $\begin{array}{c}0,27 \\
(0,23)\end{array}$ & $\begin{array}{c}3,40 \\
(0,89)\end{array}$ & $\begin{array}{l}14,97 \\
(1,00)\end{array}$ \\
\hline
\end{tabular}

Keterangan: Nilai merupakan rata-rata dari tiga pengukuran. Angka dalam kurung merupakan standar deviasi

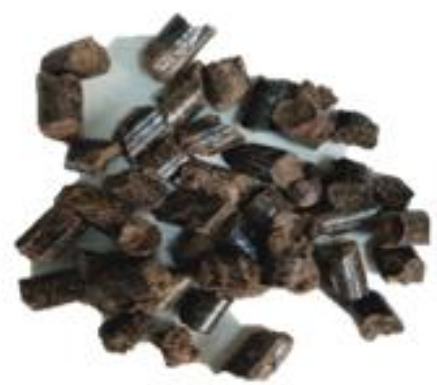

(a)

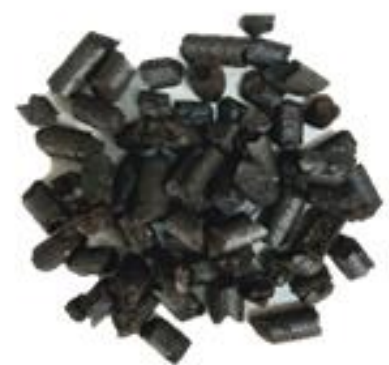

(b)

Gambar 2. Warna Pelet TKKS: (a) Sebelum Torefaksi/Kontrol, (b) Torefaksi pada Suhu $280^{\circ} \mathrm{C}$ Durasi 20 Menit dengan EF

gelap. Perubahan warna dengan kisaran 45-50\% terjadi pada suhu $120^{\circ} \mathrm{C}$ ke $150^{\circ} \mathrm{C}$ dan suhu $120^{\circ} \mathrm{C}$ ke $180^{\circ} \mathrm{C}$ terjadi sekitar $\pm 75 \%$. Penelitian sebelumnya juga menunjukkan bahwa parameter warna $L^{*}, a^{*}$, dan $b^{*}$ pelet sebelum torefaksi (kontrol) menurun seiring dengan meningkatnya suhu torefaksi (Sulistio et al., 2020). Menurut Rubiyanti et al. (2019) bahwa warna pelet kayu karet berubah total setelah torefaksi pada suhu $200^{\circ} \mathrm{C}-300^{\circ} \mathrm{C}$. Hasil penelitian Hadiyane (2011) menunjukkan bahwa peningkatan suhu mulai dari $170 " 190^{\circ} \mathrm{C}$ terjadi perubahan warna kayu menjadi lebih gelap secara berangsur-angsur. Perubahan warna terjadi karena adanya perubahan suhu yang menyebabkan adanya relokasi lignin serta degradasi komponen kimia kayu.

\subsection{Kerapatan}

Hasil penelitian menunjukkan bahwa kerapatan pelet TKKS menurun setelah torefaksi. Nilai kerapatan pelet TKKS kontrol sebesar 0,58 g/ $\mathrm{cm}^{3}$ menurun setelah torefaksi menjadi $0,48 \mathrm{~g} /$ $\mathrm{cm}^{3}$ (Tabel 2). Hasil penelitian sejalan dengan hasil penelitian Sulistio et al. (2020) yang menyatakan bahwa proses torefaksi mengakibatkan penurunan nilai kerapatan pada pelet kayu jabon ukuran panjang dan pendek. Pelet ukuran panjang dan pendek sebelum ditorefaksi memiliki nilai kerapatan sebesar 1,05 $\mathrm{g} / \mathrm{cm}^{3}$ dan $0,97 \mathrm{~g} / \mathrm{cm}^{3}$. Kerapatan pelet menurun nilai kerapatannya dengan meningkatnya suhu torefaksi. Kerapatan pelet ukuran panjang dan pendek menurun hingga $0,87 \mathrm{~g} / \mathrm{cm}^{3}$ dan $0,75 \mathrm{~g} /$ $\mathrm{cm}^{3}$ setelah ditorefaksi dengan EF. Perubahan kerapatan bisa terjadi karena disebabkan pengurangan bobot masa dan volume selama proses perlakuan panas berlangsung (Hidayat et al., 2015; Hidayat et al. 2016).

\subsection{Kadar Air}

Hasil penelitian menunjukkan bahwa nilai kadar air setelah torefaksi menjadi turun. Nilai kadar air dapat dilihat pada Tabel 3 dengan ukuran nilai $6,66 \%$ melalui perlakuan electric furnace, dan kontrol memiliki kadar air 11,56\%. Nilai kadar air terkecil terdapat pada perlakuan electric furnace dan nilai kadar air terbesar terdapat pada sampel kontrol yaitu 7,81\%. Hal ini sejalan dengan penelitian yang telah dilakukan oleh Asip et al. (2014) menyatakan bahwa kadar air pada briket memiliki kecenderungan untuk menurun seiring dengan meningkatnya suhu suhu perlakuan.

Menurut Sriharti dan Salim (2011), rendahnya kadar air yang diperoleh disebabkan oleh lamanya pengeringan yang dilakukan, 
Tabel 2. Kerapatan Pelet TKKS

\begin{tabular}{cccc}
\hline Perlakuan & Suhu $\left({ }^{\circ} \mathbf{C}\right)$ & Durasi (Menit) & Kerapatan $\mathbf{g r} / \mathbf{c m}^{\mathbf{3}}$ \\
\hline Kontrol & & & $0,58(0,04)$ \\
Electric Furnace & 280 & 20 & $0,48(0,08)$ \\
\hline
\end{tabular}

Keterangan: Nilai merupakan rata-rata dari tiga pengukuran. Angka dalam kurung merupakan standar deviasi

Tabel 3. Kadar Air Pelet TKKS

\begin{tabular}{cccc}
\hline Perlakuan & Suhu $\left({ }^{\circ} \mathbf{C}\right)$ & Durasi (Menit) & Kadar Air (\%) \\
\hline Kontrol & & & $11,54(0,43)$ \\
Electric Furnace & 280 & 20 & $6,66(0,89)$ \\
\hline
\end{tabular}

Keterangan: Nilai merupakan rata-rata dari tiga pengukuran. Angka dalam kurung merupakan standar deviasi

sebagaimana halnya briket, pelet juga dibuat melalui proses pemadatan. Torefaksi dengan menggunakan suhu yang semakin tinggi menyebabkan penguapan air dan bahan ekstraktif serta degradasi hemiselulosa sehingga kadar airnya semakin menurun (Widarti, 2017). Kandungan air pada pelet biomassa yang rendah menyebabkan kualitas pelet semakin meningkat dan berpengaruh terhadap nilai kalor sehingga lebih mudah untuk dinyalakan (Gultom et al., 2017).

Penelitian yang dilakukan oleh Susilowati et al (2017) yang menyatakan bahwa menurunnya kadar air dan kadar volatil diakibatkan oleh semakin banyaknya air dan komponenkomponen volatil yang menguap seiring dengan meningkatnya suhu torefaksi. Menurut Obernberger et al. (2004) kadar air yang tinggi dapat menurunkan nilai kalor, sehingga akan mengurangi efisiensi konversi dan kinerja sejumlah energi yang digunakan untuk menguapkan air tersebut, sedangkan kadar air yang rendah akan meningkatkan efisiensi dan kinerja dalam melancarkan keberlanjutan pembakaran.

\subsection{Ketahanan Terhadap Air}

Pengujian ketahanan terhadap air dilakukan untuk mengetahui ketahanan pelet terhadap kecepatan dalam menyerap air selama batas waktu sampai 12 jam. Sampel pelet biomassa yang dilakukan perendaman memberikan reaksi yang berbeda-beda. Terlihat pada Gambar 4 sampel pelet kontrol memiliki tingkat ketahanan yang sangat rendah yaitu pada menit ke- 5 sudah mengalami kerusakan pada bagian pelet, sedangkan sampel dengan perlakuan menggunakan electric furnace, memiliki ketahanan yang kuat, pada menit ke-30 kondisi struktur pelet kontrol sudah mulai hancur dan ada yang menyebar ke air. Namun pada jam ke1 sampel perlakuan kontrol sudah mulai mengalami kerusakan struktur hingga seluruh bagian menyebar ke air dan terurai, begitu pula sampai jam ke-12. Sampel pelet dengan perlakuan electric furnace memiliki ketahanan yang lebih baik dibandingkan dengan sampel kontrol.

Kerusakan struktur pelet biomassa disebabkan karena kerapatan pada pelet biomassa masih tergolong sangat rendah sehingga air masuk melalui celah pelet dengan sangat cepat. Berdasarkan hasil pengujian kadar air dan daya serap air, torefaksi mengubah sifat higroskopis pelet dari hidrofilik (cenderung menyerap air) menjadi hidrofobik (tahan terhadap air). Sifat hidrofobik pelet sangat menguntungkan dalam penyimpanan maupun aplikasinya. Biomassa yang bersifat hidrofilik lebih mendukung aktivitas biologis seperti dekomposisi, jamur, dan pembusukan ketika ditumpuk (disimpan) dalam volume dan durasi tertentu (Ashman et al., 2018); Evangelista et al, 2018). Penelitian Rubiyanti et al. (2019) menyatakan bahwa pada sampel kontrol, pelet sudah mulai mengalami pengembangan pada menit ke-1.

Pengembangan pelet kontrol semakin besar seiring dengan bertambahnya waktu perendaman hingga akhirnya disintegrasi pelet terjadi setelah 1 jam perendaman dan semakin terlihat jelas setelah 24 jam. Hal ini menunjukkan bahwa ekstraktif pada pelet belum seluruhnya teroksidasi setelah torefaksi pada suhu $200^{\circ} \mathrm{C}$ dan $250^{\circ} \mathrm{C}$. Penelitian yang dilakukan Aripin (2013) menyatakan bahwa bagas tebu yang tidak ditorefaksi mengalami kenaikan moisture 


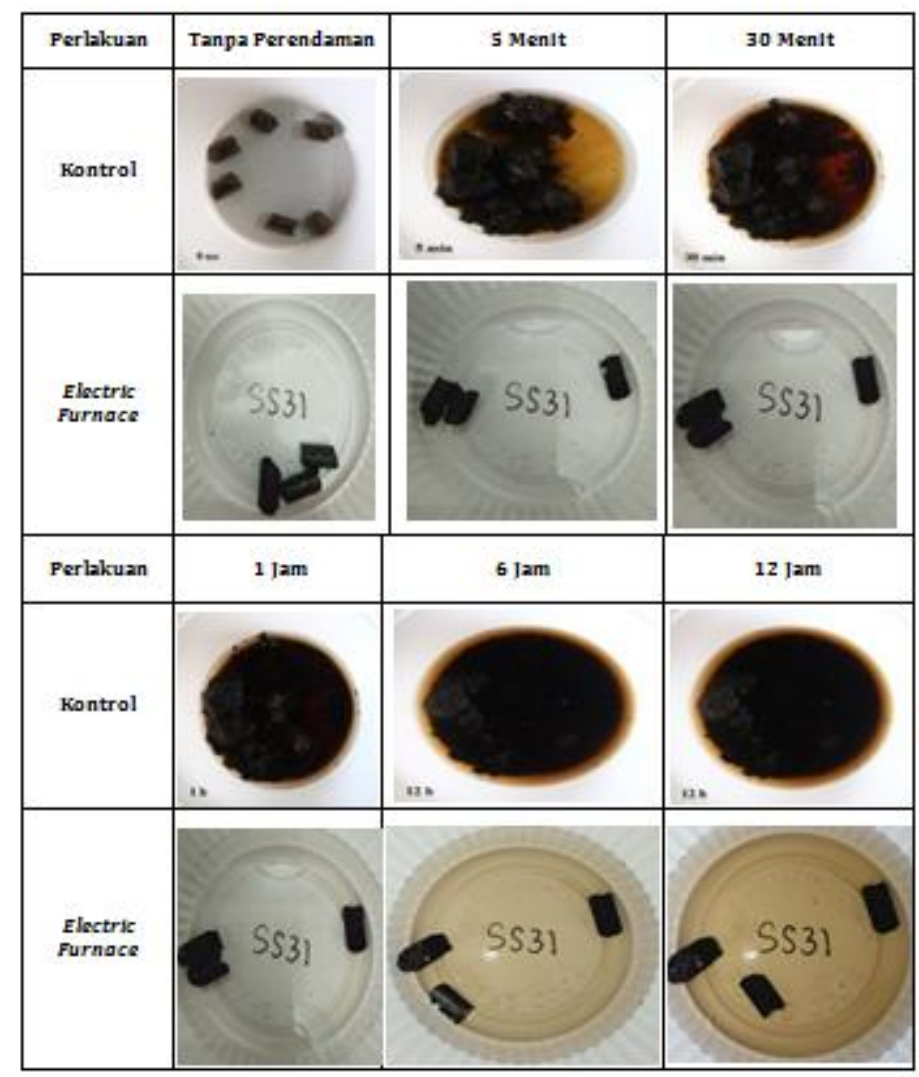

Gambar 4. Hasil Uji Ketahanan Terhadap Air dari Pelet Tandan Kosong Kelapa Sawit

content yang tinggi 5,56\% pada menit ke-30 dan terus meningkat hingga $7,35 \%$ pada menit ke240. Hal tersebut terjadi karena bagas tebu memiliki kemampuan menyerap air yang tinggi. Kemampuan bagas tebu menyerap air disebabkan karena adanya kandungan polisakarida dalam bentuk hemiselulosa, selulosa, dan lignin.

\section{KESIMPULAN}

Torefaksi menggunakan electric furnace menyebabkan terjadinya perubahan warna secara visual yang semakin gelap. Nilai kerapatan pelet TKKS kontrol sebesar 0,58 g/ $\mathrm{cm}^{3}$ menurun setelah torefaksi menjadi $0,48 \mathrm{~g} /$ $\mathrm{cm}^{3}$. Persentase kadar air pada sampel kontrol sebesar $11,56 \%$, sampel dengan perlakuan electric furnace memiliki kadar air terendah sebesar 6,66\%. Ketahanan terhadap air pelet dengan perlakuan electric furnace memiliki ketahanan yang lebih baik dibandingkan dengan sampel kontrol. Kerusakan struktur pelet biomassa disebabkan karena kerapatan pada pelet biomassa masih tergolong sangat rendah sehingga air masuk melalui celah pelet dengan sangat cepat.

\section{UCAPAN TERIMAKASIH}

Penelitian ini didukung oleh riset grant BPDPKS (Badan Pengelola Dana Perkebunan Kelapa Sawit) Nomor Kontrak PRJ-85/DPKS/2018.

\section{DAFTAR PUSTAKA}

Aripin, P. 2013. Pengaruh Torefaksi Terhadap Sifat Fisik Pellet Biomassa yang Dibuat Dari Bahan Baku Bagas Tebu. (Skripsi). Fakultas Teknik. Universitas Indonesia. Jakarta.

Ashman, J. M., Jones, J. M., and Williams, A. 2018. Some Characteristics of the Self-Heating of the Large Scale Storage of Biomass. Fuel Processing Technology 174: 1-8. DOI: 10.1016/j.fuproc.2018.02.004.

Asip, F., Anggun, T, dan Fitri, N. 2014. Pembuatan briket dari campuran limbah plastik ldpe, 
tempurung kelapa dan cangkang sawit. Jurnal Teknik Kimia. 2(2): 45-54.

Basu, P. 2013. Biomass Gasification, Pyrolysis and Torrefaction-Practical Design and Theory. Buku. Academic Press. San Diego.145 Hlm.

Esteves, B. M., and Pereira, H. M. 2009. Wood Modification by Heat Treatment: A Review BioResources 4(1): 370-404.Direktorat Jenderal Perkebunan. 2014. Statistik Perkebunan Indonesia Kelapa Sawit Indonesia 2013-2015. Direktorat Jenderal Perkebunan. Jakarta.

Evangelista, B., Arlabosse, P., Govin, A., Salvador, S., Bonnefoy, O., and Dirion, J. La. 2018. Reactor Scale Study of Self-Heating and Self-Ignition of Torrefied Wood in Contact with Oxygen. Fuel 214: 590-596. DOI: 10.1016/j.fuel.2017.11.048.

Gultom, R. N., Sulaeman, R, dan Budiani, E.S. 2017. Pemanfaatan limbah kayu jabon dan limbah serat sawit sebagai bahan baku briket arang. Jurnal Fakultas pertanian Ur. 4(1): 1-5.

Hadiyane, A. 2011. Perubahan Sifat-Sifat Komponen Penyusun Kayu, Struktur Sel Kayu dan Sifat-Sifat Dasar Kayu Terdensifikasi Secara Parsial. (Skripsi). Sekolah Pascasarjana. Institut Pertanian Bogor. Bogor. $176 \mathrm{hlm}$.

Hidayat, W., Febrianto, F., Purusatama, B. D., and Kim, N. H. 2018. Effects of Heat Treatment on the Color Change and Dimensional Stability of Gmelina arborea and Melia azedarach Woods. in: E3S Web of Conferences. 68:03010. DOI: 10.1051/ e3sconf/20186803010.

Hidayat, W., Qi, Y., Jang, J. H., Park, B. H., Banuwa, I. S., Febrianto, F., and Kim, N. H. 2017. Color Change and Consumer Preferences towards Color of HeatTreated Korean White Pine and Royal Paulownia Woods. Journal of the Korean Wood Science and Technology 45(2): 213-222. DOI: 10.5658/ WOOD.2017.45.2.213.
Hidayat, W., Qi, Y., Jang, J. H., Febrianto, F., Lee, S. H, dan Kim, N. H. 2016. Effect of treatment duration and clamping on the properties of heat-treated okan wood. BioResources. 11(4): 10070-10086. North Carolina State University. DOI: 10.15376/ biores.11.4.10070-10086.

Hidayat, W., Jang, J. H., Park, S. H., Qi, Y., Febrianto, F., Lee, S. H, dan Kim, N. H. 2015. Effect of temperature and clamping during heat treatment on physical and mechanical properties of Okan (Cylicodiscus gabunensis [Taub.] Harms) wood. BioResources. 10(4): 6961-6974. DOI: 10.15376/biores.10.4.6961-6974.

Karlinasari, L., Yoresta, F. S, dan Priadi, T. 2018. Karakteristik perubahan warna dan kekerasan kayu termodifikasi panas pada berbagai suhu dan jenis kayu. Jurnal Ilmu Teknologi Kayu Tropis. 16(1): 68-82.

Nur, H. 2014. Karakteristik Kelapa Sawit Sebagai Bahan Baku Bioenergi. Buku. PT. Insan Fajar Mandiri Nusantara. Bogor.

Obernberger, L dan Thek, G. 2004. Physical Characterisation and Chemical Composition of densified Biomass Fuels with Regard to Their Combustion Behavior, Biomass and Bioenergy, 27: 653-669.

Panwar, V., Prasad, P., \& Wasewar, K. L. 2011. Biomass residue briquetting and characterization. Journal of Energy Engineering ASCE. 4(7):108-114.

Rani, I. T., Hidayat, W., Febryano, I. G., Iryani, D. A., Haryanto, A., and Hasanudin, U. 2020. Pengaruh Torefaksi terhadap Sifat Kimia Pelet Tandan Kosong Kelapa Sawit. Jurnal Teknik Pertanian 9(1): 63-70. DOI: 10.23960/jtep-lv9i1.63-70.

Rubiyanti, T., Hidayat, W., Febryano, I. G., and Bakri, S. 2019. Karakterisasi Pelet Kayu Karet (Hevea brasiliensis) Hasil Torefaksi dengan Menggunakan Reaktor Counter-Flow Multi Baffle (COMB). Jurnal Sylva Lestari 7(3): 321-331. DOI: 10.23960/jsl37321331. 
Sriharti Dan Salim, T. 2011. Pengaruh Komposisi Bahan Terhadap Karakterisasi Pellet Limbah Biji Jarak Pagar Uatropha Curcas Linn). Teknologi Indonesia.. 34: 40-48.

Sulistio, Y., Febryano, I. G., Yoo, J., Kim, S., Lee, S., Hasanudin, U., and Hidayat, W. 2020. Pengaruh Torefaksi dengan Reaktor Counter-Flow Multi Baffle (COMB) dan Electric Furnace terhadap Pelet Kayu Jabon (Anthocephalus cadamba). Jurnal Sylva Lestari 8(1): 65-76. DOI: 10.23960/ jsl1865-76

Susilowati., Komalasari, dan Helwani, Z. 2017. Bahan bakar padat dari pelepah sawit menggunakan proses torefaksi; variasi suhu dan ukuran bahan baku. Jurnal Fakultas Teknik. 4(1): 1-4.
Syamsiro, M. 2016. Peningkatan kualitas bahan bakar padat biomassa dengan proses densifikasi dan torrefaksi. Journal Mek. Sist. Termal. 1(1): 7-13.

Valverde, J. C., and Moya, R. 2014. Correlation and Modeling between Color Variation and Quality of the Surface between Accelerated and Natural Tropical Weathering in Acacia mangium, Cedrela odorata and Tectona grandis Wood with Two Coating. Color Research and Application 39(5): 519-529. DOI: $10.1002 /$ col.21826.

Widarti, A. 2017. Energi Terbarukan dari Batang Kelapa Sawit: Konversi Menggunakan Proses Torefaksi. 